\title{
Corporate Social Responsibility Beyond Borders: US Consumer Boycotts of a Global Company over Sweatshop Issues in Supplier Factories Overseas
}

\begin{abstract}
The current research examines the effects of individualizing moral foundations (i.e., fairness and care) on consumer boycotts against the US company that is entangled in an alleged sweatshop issue at a supplier's factory in a developing country. On the basis of moral foundations theory (MFT), the current study tests six hypotheses demonstrating the theoretical mechanism in which individualizing moral foundations have an impact on consumer boycott intentions through blame attributions and anger. Using a representative US sample of 1124 people, a national survey was conducted to test the proposed structural equation model. As predicted, results of mediation analysis showed that individualizing foundations, comprising the fairness/care values, led to boycott intentions fully mediated by blame attribution and anger.
\end{abstract}

Keywords:

moral foundations theory; global CSR; sweatshop; anger; blame attributions; boycott intentions 


\section{Corporate Social Responsibility Beyond Borders: US Consumer Boycotts of a Global Company over Sweatshop Issues in Supplier Factories Oversea}

Globalization has spawned vast numbers of multinational corporations (MNCs)—global inter-organizational systems comprising headquarters and different national subsidiaries, as well as a body of external organizations with which different units of the MNCs interact (Ghoshal \& Bartlett, 1990). As interconnected inter-organizational systems, MNCs are better able to pursue internal management efficiency while reducing operating costs in multiple countries (Lim, 2010; Schwarz \& Fritsch, 2014). Due to this structural configuration, many MNCs are enjoying the cost efficiency. On the other hand, however, they are prone to potential negative spillovers from the incidents that occurred in developing countries they have business operations in. Regarding such challenges, Molleda and his colleagues (Molleda, Connolly-Ahern, \& Quinn, 2005; Molleda \& Quinn, 2004) proposed the notion of cross-national conflict shifting. This explains the phenomenon wherein the issue or crisis occurring in a country where an MNC's subsidiary or manufacturing factory is located is felt in other countries, including the MNC's home country. In particular, MNCs have been criticized by consumers and activists in their home countries for their failure of oversight of human rights violations at those factories abroad (Molleda et al., 2005; Yu, 2008) (Yu, 2008).

An emerging question is why consumers in the home country of the global MNC's parent company react to problems arising at factories in a host country—a country where MNCs subsidiaries undertake parent companies' work, and engage in boycotting behaviors. Previous research on cross-national issue/crisis shifting has been limited to content analysis (e.g., media coverage of an international bribery scandal that involves a consortium of Canadian transnational firms and a host country's government) (Molleda et al., 2005) or case study (e.g., negative 
spillovers of a Coca-Cola Scare in Belgium to Spain and France) (Taylor, 2000). Also apparent is a lack of research explaining the theoretical mechanism whereby consumers in the MNC's home country react to a crisis that crosses borders.

A related question is who is more likely to participate in boycotting a US company that outsources manufacturing to a supplier in a developing country, when the supplier allegedly is involved in socially-irresponsible business practices. Moral foundations theory (MFT) (Graham, Haidt, \& Nosek, 2009) can be a useful theoretical background to explain consumer activism eruptions in the global trade system. Literature in moral psychology identifies moral foundations as the resource through which an individual consumer develops his or her own moral intuitions governing ethical perceptions, judgment and behaviors (Graham et al., 2009). With regard to consumer behaviors, MFT suggests that moral values associated with political orientation and/or ideology could have a different impact on consumer activism (Kidwell, Farmer, \& Hardesty, 2013; Watkins, Aitken, \& Mather, 2016). On the basis of MFT, the current study attempts to explore the impact of consumers' moral foundations on their judgments about blame attribution, emotional responses, and boycott intentions. The current study aims to examine (1) how individuals' moral foundations lead to boycotting behaviors in the case of employee suicide at an outsourced supplier; (2) how blame attributions and anger influence consumer boycott intentions; and (3) whether blame attributions and anger mediate the impact of consumers' moral foundations on boycott intentions.

\section{Theoretical Backgrounds}

\section{MNCs' CSR and International Public Relations}

Due to rising transnational activist organizations and advocacy networks raising issues related to human rights and working conditions (Molleda et al., 2005; Ruggie, 2004) in MNCs' 
supply chains overseas, MNCs face new challenges. These global activists and their alliances transcending borders have called for new standards and practices in public relations of the MNCs. For example, the Foxconn employees' suicide case that escalated into a global scale crisis decreased the legitimacy of Apple as a responsible company, and sparked much criticism and a string of boycott calls (Anner, 2012). Despite mounting pressure from global activists, MNC headquarters' public relations appears to be reactive and irresponsible. Substantial research across various disciplines, including sociology (Banerjee, 2008), public relations (Munshi \& Kurian, 2005), and business (Bliss, 2002; Scherer, Palazzo, \& Baumann, 2006), has critically discussed global branded marketers' problems in managing relationships and communication with their key stakeholders. However, relatively less is known about why key stakeholders living in the home country of an MNC's parent company actively react to such tragic events as the Bhopal disaster (Munshi \& Kurian, 2005), Nike's sweatshop labor crisis (Russell, Russell, \& Honea, 2016), and Foxconn's suicide crisis (Xu \& Li, 2013) that happened at the supplier's factories in the host country. Key stakeholders' reactions are important in that these can and do influence the corporate behavior of MNCs fearing consumer boycotts and the negative publicity following a call for boycotts online (Bliss, 2002).

\section{Consumer boycotts in the context of CSR failure of MNCs}

A consumer boycott is defined as consumer's intended action, by means of withholding purchase of the company's product or services or discouraging others from purchases or consumption, to coerce the target company into ethical and prosocial business decision and/or practices (Sen, Gurhan-Canli, \& Morwitz, 2001). Consumer boycotts increase with the trend of ethical consumerism (John \& Klein, 2003; Lim, 2017) and the emergence of empowered 
consumers equipped with new communication technologies (Braunsberger \& Buckler, 2011;

Kähr, Nyffenegger, Krohmer, \& Hoyer, 2016).

A consumer boycott is instrumental in that its goal is not so much to cause irreparable harm to a company as it is coerce that the company to rectify the issue or problem and restore consumer trust (Kähr et al., 2016). Consumer boycott involves such diverse negative consumer behaviors as call for banning products from a company, petitions for legislation (Braunsberger \& Buckler, 2011) and negative word of mouth (NWOM) (Antonetti \& Maklan, 2016; Grappi, Romani, \& Bagozzi, 2013; John \& Klein, 2003; Lim, 2017). In the age of social media, consumer boycott behaviors can be identified in two dimensions. The first dimension, called negative word-of-mouth (WOM) behavior, involves consumers who actively engage in spreading negative words regarding the company that committed socially irresponsible acts. These negative WOM behaviors in social media often are represented by the call for boycotts using a unique hashtag that reminds other users of the urgency and seriousness of the issue. The second dimension, called instrumental boycotts, involves consumers who resort to a collective level of problem solving by petitioning the case to authorities and regulatory bodies. Russell et al. (2016) called the former individual boycott behavior while they labeled the latter collective level boycotting behavior.

In the current study, we considered the two types of consumer boycott behaviorsnegative WOM and instrumental boycott behaviors. The negative word-of-mouth (NWOM) boycotts refer to consumer actions of "saying negative things, recommending against purchasing, and discrediting the company" to show one's dissatisfaction with and anger toward the company that is socially or ethically irresponsible (Grappi et al., 2013, p. 1815). The instrumental boycotts refer to collective consumer actions against the company that committed egregious business 
misconducts, in order to bring about positive social change. Instrumental boycotts are called for in order to coerce a target company to change or discontinue the egregious behavior (Friedman, 1991). The instrumental boycott purports to ban products from an ethically-problematic company through petitions for legislation together with other like-minded consumers (Braunsberger \& Buckler, 2011).

As noted earlier, globalization has expanded the boundaries and the scope of potential tensions between global businesses and diverse local stakeholders. While various motivations drive consumers to boycotts, ethical judgments are key motivators for consumers to participate in boycotts. Particularly, moral motivations are the key driver of consumer participation in boycotts against global companies (Hoffmann \& Müller, 2009). Although researchers suggested that moral values underlie consumer boycott behaviors, little research has examined explicitly whether the moral foundations related to fairness and care actually do impact consumer boycott behaviors. To fill that research gap, the current study examines the relationship between consumer boycott behaviors and individualizing moral foundations - that is, care/harm and fairness/justice. In addition, the current research is interested in whether moral foundations directly or indirectly influence consumer boycott behaviors. Some researchers suggest that consumer boycott participation may not be affected directly by moral foundations and that their behaviors are more driven by negative appraisals of the company's business decisions/ practices and the anger evoked as a result of such appraisals (Lim, 2017; Wildermuth, De Mello e Souza, \& Kozitza, 2017). As such, we identified two factors that potentially mediate the impact of moral foundations on boycott behaviors. Blame attribution and anger are two factors potentially mediating the impact of moral foundations on boycott intentions, when consumers are exposed to a crisis caused by a supplier's immoral business practices and subsequent tragic human loss 
(Wildermuth, et al., 2017; Zourrig et al, 2009). In the following sections, we review the literature explaining the relationship between moral foundations and the two factors.

\section{Effect of moral values on blame attributions}

Moral psychologists (Graham et al., 2009; Graham et al., 2011) identified five moral foundations, namely 1) harm/care, 2) fairness/reciprocity, 3) in-group/loyalty, 4)

authority/respect, and 5) purity/sanctity. Although conservatives support all five, they are inclined to achieve higher levels of authority and loyalty than liberals. Graham and his colleagues (2009) consolidated those foundations concerned with authority, loyalty to ingroup, purity, and categorized them as binding foundations. In contrast, liberals are more inclined to support such moral foundations as fairness, caring and avoidance of harm in pursuit of social justice, which is categorized as individualizing foundations (Graham et al., 2009).

Harm/care constitutes individuals' moral foundations often activated when observing others' suffering, which is closely related to compassion or empathy (Graham et al., 2011). In addition, care/harm and fairness are typically associated with liberal political morality. These moral foundations buttress and protect individual rights in society (Smith, Aquino, Koleva, \& Graham, 2014) and, with these values, individuals are more concerned about equitable treatment of other individuals to maximize everyone's autonomy and welfare (Graham et al., 2011). These foundations were strong predictors for the prosocial behaviors such as donating to the poor (Low \& Wui, 2016; Winterich, Zhang, \& Mittal, 2012).

According to MFT, people tend to reason their ethical judgment based on their appraisals of an ethical issue. When observing a firm's egregious behavior, individuals want to understand what went wrong, how it went wrong, and who was responsible for the moral failure. Business researchers have been interested in the process by which individuals make understanding of who 
caused the current problem. Such cognitive processing helps consumers identify where responsibility lies, which is called blame attribution (Antonetti \& Maklan, 2016).

A body of business research (Antonetti \& Maklan, 2016; Bradfield \& Aquino, 1999; Donoghue \& de Klerk, 2013; Donoghue, Strydom, Andrews, Pentecost, \& de Klerk, 2016; Stephens \& Gwinner, 1998; Zourrig, Chebat, \& Toffoli, 2009) has examined consequences of blame attributions and showed that negative consumer behavior is a function of consumers' blame attributions. A potential link between blame attributions and actions based on restorative justice intentions was demonstrated earlier in Bradfield and Aquino's (1999) study. Applying a cognitive appraisal theory approach, Bradfield and Aquino (1999) considered the revenge or punishment of business wrongdoings as individuals' strategies to cope with negative feelings or personal offense. They found that individuals' behaviors to enact restorative justice increased, as the perceived severity of the offense increased. Zourrig et al. (2009) showed a causal relationship where the initial appraisal of harm/loss and fairness could influence consumers' blame attributions.

Based on the aforementioned research, the current research assumes that individualizing moral foundations will have a direct impact on blame attributions to the US parent company for dire labor conditions and subsequent employee suicidal incidents in a supplier's factory in the host country. This leads us to propose the following hypothesis:

H1. The US consumers' individualizing moral foundations will have a direct effect on their blame attributions to the parent company of the $\mathrm{MNC}$ for the labor rights violations at a supplier's factories in a host country.

\section{Effect of moral values on anger}


The role of emotional outrage in consumers' revengeful behaviors is well documented in business research (Bradfield \& Aquino, 1999; Lindenmeier, Schleer, \& Pricl, 2012; Nerb \& Spada, 2001; Zourrig et al., 2009). Moral outrage refers to "anger provoked by the perception that a moral standard — usually a standard of fairness or justice — has been violated" (Batson et al., 2007, p. 1272). Moral outrage is often distinguished from empathetic anger that is evoked after witnessing unfair or unjust treatment of others by an individual or an organization (Batson et al., 2007). In other words, empathetic anger is a discrete emotion that is formed in response to the situation in which someone else is being treated unfairly (Gibson \& Callister, 2010). Business researchers noted that the perceived fairness is essential to elicit feelings of anger (Antonetti \& Maklan, 2016).

In the case of unfair treatment of employees at a supplier's factory in a host country, emotional reactions to such unfairness can be formed as a result of cognitive appraisals of the situation (Batson et al., 2007). For instance, appraisal of the situation in which the interests of someone else for whom I care have been thwarted, can evoke empathic anger (Batson et al., 2007). The distinction between moral outrage and anger is needed because they entail different types of behavioral consequences. When moral outrage occurs, moral emotions can be relieved by "reestablishing and reaffirming the violated moral standards," whereas empathetic anger induces "direct action toward retaliation and promoting the interests of the cared-for other" (Batson et al., 2007, p. 1273).

Antonetti and Maklan's (2016) research on emotional reactions to egregious corporate behavior revealed that the severity of moral violation directly influenced moral outrage whereas blame attribution did not have a direct effect on moral outrage. One notable finding from their study is that emotional outrage strongly correlates with NWOM. In discussing the results of the 
study, Antonetti and Maklan (2016) called for research examining the role of anger in boycotts. In making a logical connection between emotional reactions to irresponsible corporate behavior, we believe that moral values play an important role in inducing consumer anger directed toward the company. For instance, Vassilikopoulou et al. (2011) found that individuals' ethical beliefs, along with their perceived degree of ethical violation, elicited anger during an organization's crisis caused by product harm. They showed that consumers exhibited different levels of anger, according to their ethical beliefs representative of individualizing moral foundations. Therefore, we posit the following hypothesis:

H2. The US consumers' individualizing moral foundations will have a direct effect on their anger directed toward the parent company of the MNC for the labor rights violations at a supplier's factories in a host country.

\section{Effect of blame attributions and anger on consumer boycotts}

When a crisis occurs, people tend to blame an organization according to the degree to which an organization's fault caused it and/or on how preventable that crisis was (Coombs, 2007). People's blame-attribution tendency likely increases as the consequence or severity of the incident increases (Bradfield \& Aquino, 1999; Walster, 1966).

Zourrig et al. (2009) proposed a consumer revenge model in which consumers' cognitive appraisals of blame attributions relate closely to their revenge behaviors. These vindictive measures would include NWOM, vindictive complaining, switching to an alternative (Grégoire \& Fisher, 2008) or calling for boycotts of the company’s products (Braunsberger \& Buckler, 2011). That is, the more the blame attributed to the company by individual consumers, the more the boycott behaviors conducted by the consumer. Nerb and Spada (2001) examined how varying 
degree of blame ascription to an agent allegedly responsible for a negative environmental event, could affect boycott behaviors. Hence, we posit the following hypothesis:

H3: The US consumers' boycott intentions will increase as their blame attributions toward the parent company of the MNC increase.

Anger is known as a strong predictor of consumers' intention to participate in boycotts against a firm's egregious behavior. Considerable research (Braunsberger \& Buckler, 2011; John \& Klein, 2003; Lindenmeier et al., 2012; Makarem \& Jae, 2016; Xie, Bagozzi, \& Grønhaug, 2015) suggests that consumer boycotts are driven primarily by anger at a company's egregious behavior. Some researchers further argue that unfair treatment of others tends to invoke empathic anger, which can be a stronger precursor of consumer participation in boycotts (O'Mara, Jackson, Batson, \& Gaertner, 2011). In other words, empathic anger that consumers build against the company causing the crisis is a major factor behind boycott behavior. For example, people tend to act against the company causing the negative event (although negativity is not so severe) especially when they sympathize with victims (Walster, 1966). Focusing on the role of empathic anger on boycott, this study posits the following hypothesis regarding the direct effect of anger on boycott:

H4: The US consumers' boycott intentions will increase as their anger toward the parent company of the MNC increase.

\section{Indirect effect of moral values on consumer boycotts}

Previous research (Hosmer \& Kiewitz, 2005) in business ethics suggests that an individual's moral values and intuitions drive him or her to boycott behaviors when encountering an egregious behavior of a company or its CEO. Several studies in consumer psychology have applied MFT to predict such diverse consumer behaviors as sustainable consumption practices 
(Kidwell et al., 2013; Watkins et al., 2016), donations (Winterich et al., 2012), diet choice (De Backer \& Hudders, 2015) and so forth. However, to date, no study is known to apply MFT to examine consumers' behavioral reactions to an MNC's CSR failure in its global supply chains. Nonetheless, the association between moral foundation and boycotts can be assumed from the existing body of business research (Russell et al., 2016; Vassilikopoulou et al., 2011). For instance, Russell et al. (2016) revealed that participants in a high-environmentalconsciousness group had greater boycotting behaviors than a low-environmental-consciousness group had, when they observed a company's ethical violation. Kidwell et al.'s (2013) study demonstrated that the individualizing foundations were positively associated with sustainable consumption behaviors and protest behaviors of consumers in New Zealand. In an experimental study, they showed that persuasive appeals based on individualizing foundations were more effective in inducing ethical decisions and behaviors of liberals, whereas conservatives were more responsive to persuasive appeals evoking binding foundations. Using a structural equation modeling approach, Vassilikopoulou et al. (2011) developed perhaps the most sophisticated model explaining the role of moral values on consumer behaviors against the company that was involved in a product-harm crisis. Although they used purchase intentions as an endogenous variable, the model provided managerial and theoretical implications to business researchers who aim to reveal the effects of moral foundations on consumer boycotts. Their study results clearly showed that moral beliefs led to negative consumer behaviors mediated by blame attributions and anger.

Other literature in business research also suggests that the effect of moral foundations on punitive actions or boycotts can be mediated by anger. Lindenmeier and his colleagues (2012) argue that consumer anger is a compound emotion arising in response to a moral violation in 
business practice and standard. Their view is that anger is subsequent to consumers' appraisals of a certain event involving a firm's ethical violations based on their perceived moral inequality and the relevance of the event to their lives (Lindenmeier et al., 2012). Nerb and Spada (2001) argue that ascribing ethical lapses to an agent for an environmental disaster tends to yield feelings of anger, particularly when the disaster proved to be human-made. It indicates that people feel angrier when they perceive the incident as preventable via proper precautions. Their study found that perceived blame attributions and emotions, in turn, resulted in boycotting intentions. On the basis of the aforementioned rationale, we predict that consumers' individualizing moral foundations will have an indirect effect on their intentions to boycott through blame attributions and anger.

H5: The effects of individualizing moral foundations on the US consumers' boycott intentions will be fully mediated by their blame attributions to the parent company of the MNC for the labor rights violations at a supplier's factories in a host country.

H6. The effects of individualizing moral foundations on the US consumers' boycott intentions to will be fully mediated by their anger directed toward the parent company of the MNC for the labor rights violations at a supplier's factories in a host country.

\section{Method}

\section{The Context of the Study}

In 2010, Foxconn, a Chinese supplier for Apple and the world's largest contract electronics manufacturer, faced a crisis arising from a series of employee suicides. As the suicide count mounted, media coverage and scrutiny concomitantly increased. Critics (e.g., Xu \& Li, 2013) argue that Apple was also responsible for these tragic events, on the grounds that Apple pressured Foxconn to accelerate the production to meet market demands and that it was allegedly 
indifferent to Foxconn workers' suicides. This crisis caused by several suicides of Foxconn workers and Apple's subsequent responses is the context of this study. Survey participants were presented with a vignette based on the Apple/Foxconn case, in which the names of the global company, the supplier, the country and the product were replaced by fictitious names so as to eliminate the influence of the brand image and reputation that participants might have on Apple.

\section{Sample and Procedure}

In March 2016, a web-based survey was conducted to test the proposed hypotheses. Survey participants were drawn randomly from the US panel of Qualtrics, a leading research firm. They were given credit according to the individual reward policy of the research firm. A total of 1124 respondents completed the survey. Respondents comprised $48 \%$ females, mean age $47(\mathrm{SD}=16.51)$. About $54 \%$ were married, about $40 \%$ were single, and $6 \%$ were unanswered. Of the total, participants identified their ethnicity as white or non-Hispanic (81.5\%), Hispanic American (4.3\%), African American (5.6\%) Asian American (1.9\%) and Native American $(0.9 \%)$. Among respondents, $73.2 \%$ of reported an annual household income of over US $\$ 50 \mathrm{~K}$ and $28.6 \%$ reported below US\$50K.

The web-based survey comprised measures of individualizing moral foundations, binding moral foundations, blame attributions, anger, and boycotting behaviors. Participants were exposed to a "modified" scenario extracted from a published vignette about a global conglomerate in the fashion industry. As mentioned earlier, the plot is a deliberate mimic of the real-life crisis of Foxconn but fictionalized as to names, locale, and commodity, to avoid any potential effect coming from a familiar brand.

Participants first were asked to read a vignette about a company facing a crisis due to its supplier's sweatshop issue in Africa. Participants then were asked to respond to questions 
measuring their 1) individualizing moral foundation, 2) binding moral foundation, 3) blame attributions, 4) anger, and 5) boycott intentions. The survey also measured participants' demographics that included income, ethnicity, marital status and educational levels. Total duration of the survey was approximately 15 minutes. According to Qualtrics, participants receive points for their participation, redeemable as gift cards and/or bitcoin.

\section{Measured Variables}

Individualizing moral foundations. Borrowing existing measurements from Haidt and Graham (2009), participants rated the five statements (See Table 1). "Whether someone was harmed" and four other items on a 5-point scale with endpoints: $1=$ very irrelevant, 5= very relevant $(M=3.97, S D=.90, \alpha=.87)$ : A higher mean score indicates stronger individualizing moral foundations.

Blame Attributions. To measure blame attributions $(M=3.91, S D=.83, \alpha=86)$, we adopted and modified three items (See Table 1) from Griffin, Babin, and Darden (1992) on a 5point Likert scale with endpoints: $1=$ strongly disagree, $5=$ strongly agree.

Anger. Borrowing existing measurements from Kim and Cameron (2011), this study measured anger $(M=3.60, S D=1.04, \alpha=86)$ with "I feel angry with this crisis" and three other items (See Table 1). Participants rated each item on a 5-point Likert scale with endpoints: $1=$ strongly disagree, $5=$ strongly agree.

Boycott intentions. This study measured boycott intentions $(\mathrm{M}=3.66, \mathrm{SD}=1.136, \alpha$ =86) with six items (See Table 1) adopted and modified from previous research (Klein, Smith, \& John, 2004). Participants rated each item on a 5-point Likert scale with endpoints: $1=$ strongly disagree, $5=$ strongly agree.

\section{Results}




\section{Measurement model}

To check the reliability and validity of each latent construct (Fornell \& Larcker, 1981), the measurement model was assessed by employing a confirmatory factor analysis (CFA) using Mplus 7.0 (Muthén \& Muthén, 1998-2012). Table 1 presents construct reliability (CR), average variance extracted (AVE) for each construct along with factor loadings of items that constitute each construct. Composite reliability for all constructs ranged from .84 to .92 , each of which exceeded the threshold of .70, recommended by Nunnally and Bernstein (1994). All items loaded on their corresponding latent construct exceeded .60 of factor loading values $(p<.001)$, and AVE for each construct exceeded the recommended threshold of .50. To check discriminant validity, AVE for each construct was compared to the shared variance with other constructs. Thus, square roots of AVE values for each construct were compared against correlation values involving the construct (see Table 2). All constructs including individualizing moral values (care and fairness), anger (ANG) and blame attribution (BA) satisfied requirements for discriminant validity suggested by Fornell and Larcker (1981). As shown in Table 2, the square root of AVE in each latent variable were found to be larger than other correlation values among the latent variables, indicating that discriminant validity is well established. Taken together, results indicate evidence of convergent validity and discriminant validity for all constructs of endogenous and exogenous variables (Fornell \& Larcker, 1981).

Overall, the fit statistics indicated that the measurement model provided a good fit to the data. The ratio of $\chi^{2}$ to the degrees of freedom $\left(\chi^{2} / \mathrm{df}=3.18\right)$ and the goodness-of-fit indices $(\mathrm{SRMR}=.03, \mathrm{RMSEA}=.04[90 \% \mathrm{CI}=.04-.05], \mathrm{CFI}=.98, \mathrm{TLI}=.97)$ were within the cutoff ranges $(\mathrm{SRMR} \leq .08, \mathrm{RMSEA} \leq .06, \mathrm{CFI} \geq .95$, and $\mathrm{TLI} \geq .95)$ recommended by $\mathrm{Hu}$ and Bentler (1999). 


\section{Results of Hypothesis testing}

Table 2 displays the means, standard deviations and intercorrelations of variables entered in the structural equation model. After checking with the convergent validity (Table 1) and discriminant validity (Table 2), the proposed hypotheses were tested using SEM with mediation models (Hayes, 2009) employing bootstrapping. Table 3 presents both the structural equation and the mediation models. The structural model displays the standardized point estimates, standard errors, and z scores for all the direct and indirect pathways between exogenous and endogenous variables. The mediation model shows standardized point estimates, standard errors, and $\mathrm{z}$ scores of the direct, indirect, total effect, as well as each specific indirect effect, along with bias-corrected $95 \%$ bootstrap confidence intervals. Bias-corrected bootstrap confidence intervals (CIs) were also estimated to improve the percentile bootstrap CI for the indirect effects (Preacher $\&$ Hayes, 2008). In the present analysis, 5000 bias-corrected bootstrapped resamples were used to estimate $95 \%$ CIs. Model fit indices indicated that the proposed model well fitted the observed data, based on cut-off criteria recommended by $\mathrm{Hu}$ and Bentler (1999). The ratio of $\chi^{2}$ to the degree of freedom $\left(\chi^{2} / \mathrm{df}\right)$ is 3.18. Comparative Fit Index (CFI) is .98, and Tucker-Lewis Index (TLI) is .97. Standardized Root Mean-square Residual (SRMR) is .03 and Root Mean Square Error of Approximation (RMSEA) is .04 (90\% CI = .04 - .05).

Test of H1-H2. In H1, we predicted that for the labor right violations occurring in a supplier's factory overseas, American consumers' individualizing moral foundations would have a direct effect on their blame attribution to the US company. As predicted, we found a positive effect of individualizing moral foundations on blame attributions $(\beta=.51, \mathrm{SE}=.03, \mathrm{Z}=18.83, p$ $<.001)$. Therefore, H1 was supported. 
In $\mathrm{H} 2$, we predicted that for the labor right violations occurring in a supplier's factory overseas, US consumers' individualizing moral foundations would have a positive effect on their anger directed toward the US company. Results in Table 3 show that the individualizing moral foundation has a direct, positive effect on anger directed against the company $(\beta=.42, \mathrm{SE}=.29$, $\mathrm{Z}=14.64, p<.01)$. Therefore, $\mathrm{H} 2$ also was corroborated.

\section{Test of H3-H4.}

In $\mathrm{H} 3$ and $\mathrm{H} 4$, we proposed two hypotheses that predicted the direct effect of blame attributions on boycott intentions (H3) and the direct effect of anger toward the US company on boycott intentions (H4). Results of SEM showed that blame attributions had a positive effect on boycott intentions. Therefore, H3 was supported. Anger also had a positive effect on boycott intentions, which corroborates H4. The pathway from anger to boycotts yielded a greater point estimate $(\beta=.65, \mathrm{Z}=16.91, \mathrm{p}<.001)$ than that from blame attributions to boycotts $(\beta=.24, \mathrm{Z}=$ $5.44 \mathrm{p}<.001)$

\section{Test of H5-H6.}

To test $\mathrm{H} 5$ and H6, we performed mediation analysis using the bootstrapping method. Consistent with predictions, we found full mediations of blame attributions and anger for the effect of individualizing moral foundations on boycott intentions. The total indirect effect ( $\beta$ [Bootstrap 95\% CI] $=.40[.33, .46], \mathrm{Z}=12.14, \mathrm{p}<.001)$ is strong and accounts for most of the total effect $(\beta[$ Bootstrap 95\% CI] $=.42[.35, .49], \mathrm{Z}=12.12, \mathrm{p}<.001)$. The direct effect of individualizing on boycotts is non-significant. Taken together, the mediation analysis using bootstrapping indicates the full mediation of two mediators in the relationship between individualizing foundations and boycott intentions. The specific indirect effect on boycotts through blame attributions is significant $(\beta$ [Bootstrap 95\% CI] $=.12[.07, .18], \mathrm{Z}=4.47, \mathrm{p}$ 
$<.001)$. Therefore, H5 is supported. In addition, another specific indirect effect through anger was also significant $(\beta$ [Bootstrap 95\% CI] $=.27[.21, .34], \mathrm{Z}=8.67, \mathrm{p}<.001)$. Therefore, $\mathrm{H} 6$ is corroborated.

\section{Discussion}

A firm's failure to meet agreed-on standards, or alleged unethical treatment of workers often engenders negative consumer reactions like consumer boycotts, as well as negative emotions such as anger, disgust and contempt (Grappi et al., 2013). Previous studies also suggest that blame attributions and anger are among the most important consumer responses to an MNC's irresponsibility (Vassilikopoulou et al., 2011) and that these cognitive and emotional reactions directly prompt consumer boycotts against the company that did not meet the expectations for socially responsible business operations and thereby breached consumer trust (Bliss, 2002; Lawrence, 2002). On the basis of these theoretical propositions, we have tested six hypotheses.

\section{Summary of findings and implications}

Using a survey-embedded vignette with a representative sample, the current study examined how consumers' individualizing moral foundations would influence boycott behaviors through blame attributions and anger. In so doing, the most important agenda of the current study centers on the roles of individualizing moral foundations in inducing boycott behaviors of US consumers regarding a sweatshop-like issue at a supplier in a developing country.

Based on the theories of moral foundations and boycotts, results of the current study support all the proposed hypotheses regarding the effects of individualizing moral foundations on boycotts mediated by blame attributions and anger. Results of the current study confirm that consumer anger and blame attributions play important roles in consumers' boycotting behaviors. 
To date, the present study is the first research that examines the relationship between individualizing moral values and consumer boycott intentions in the context of an MNC's irresponsibility for its supplier's labor rights violations. Results of the current research are somewhat aligned with the findings of Vassilikopoulou et al.'s (2011) research: the consumers' ethical beliefs negatively affect purchase intentions as long as consumers' anger and blame attributions toward the company increase. Therefore, we are more certain that consumers' moral values indirectly influence consumer activism against an MNC that is entangled in socially irresponsible practices in its global supply chains.

Literature in moral psychology implies that individualizing foundations, which are composed of care/harm and justice/fairness, place more emphasis on ethical concern (Crone \& Laham, 2015). In this assumption, the current research selected only the individualizing moral foundations in examining antagonistic consumer reactions to global business operations involved with sweatshop labor. As data indicate, US consumers high on individualizing moral foundations have more intentions to participate in boycotts, when their blame attributions and anger increase toward the parent company entangled in a labor issue in its supplier chain. However, this does not mean that those who endorse binding moral foundations are not concerned about the MNC's CSR failure in a developing country. Previous research suggests that liberals and conservatives respond to the same problem (e.g., climate change) differently such that any effort to persuade people in different ideological sides must consider moral foundations of each side rather than solving the problem with one-sided moral framing (Markowitz \& Shariff, 2012). Likewise, researchers should not assume that the psychological mechanism that explains the behavioral reactions of people endorsing individualizing foundations should work for people endorsing high binding foundations. In other words, the possibility exists that those who endorse binding 
foundations may develop different types of consumer behavior or response other than boycotts when encountering an MNC's CSR failure in a developing country. This is because individuals upholding binding foundations tend to be more harmonious with social order and conform to norms. Haidt and Graham (2007) noted that political conservatives have levels of ethical sensitivity differing from those of liberals. That is, conservatives are more concerned about community-oriented and duty-based morals such as in-group/loyalty and authority/respect than are liberals. Therefore, we suggest that further research replicates the current research in the context of an MNC's CSR failure or ethical transgression while considering both individualizing and binding moral foundations.

The most important finding of the current research is that the causal impact of moral foundations is not so much direct as indirect. Notably, the current research showed that blame attributions and anger were important in mediating the effect of moral foundations on boycott intentions. In other words, the current study demonstrated that US consumers' anti-sweatshop boycotts are most likely to occur among individuals of high individualizing moral values when they have the capacity to appraise the situation and identify who deserves blame, or when they are angered by unfair treatment of employees overseas. The current study's findings are consistent with the results of the consumer revenge model of Zourrig and his colleagues (2009) who identified theoretical linkages between the cognitive appraisal of moral values and revengeful behaviors mediated by blame attributions and negative emotions. When it comes to the influence of anger on boycott intentions, we confirmed that consumer anger could be crucial role in triggering consumer boycott behaviors. Results are consistent with previous research (Braunsberger \& Buckler, 2011; John \& Klein, 2003; Lindenmeier et al., 2012; Makarem \& Jae, 2016; Xie, Bagozzi, \& Grønhaug, 2015). 
Employing the bootstrapping method for the structural equation model with mediations, we examined whether individualizing moral foundations influence consumer boycotting behaviors mediated by blame attributions and anger. Results of the bootstrapped SEM revealed a strong indirect effect of individualizing foundations on boycotting behaviors through blame attributions and anger. For the endogenous variable of boycott intentions, the point estimate of the indirect effect was not only significant, but also accounted for most of the total effect. Results indicate that US consumers with individualizing foundations are likely to engage in boycotts when they are angered by unjust corporate behavior, or when they ascribe the responsibility and blame to the brand whose foreign supplier is involved in ethical violations. Taken together, results of the current study lend support for David Hume's (2006) conjecture that reason (i.e., blame attributions) and sentiment (i.e., anger) work at the same time in judging the consequences of moral determinations.

\section{Limitations and suggestions for future research}

Although the current research is well executed based on a representative sample of a research company of high repute, it may present some methodological limitations.

First, in reading the survey-embedded stimulus, some participants may have been reminded of the famous Foxconn case. To avoid a potential effect from pre-attitudes toward and/or attachment to Apple, Inc., we used a vignette embedded in a survey, presenting a fictitious company name and a fictitious locale. We believe this treatment would eliminate possible spurious effect from consumers' existing biases about the actual firm and the crisis. Despite that, participants may have been aware of the well-publicized Foxconn crisis, which may have influenced their responses. Future research might test the proposed model using a more 
controlled laboratory experiment with a control group, hiring participants to be assigned randomly to experimental and control groups.

Diametrically opposite to replacing the Apple brand with a fictitious brand might hinder estimate of actual boycott intentions, therefore might lack ecological validity. Previous research has evidenced that consumers' psychological attachment to a brand tends to lead them to shield the brand from an ethical failure (Schmalz \& Orth, 2012).

Another limitation relates to measures of moral foundations. Although we used the full items developed by Haidt and his colleagues, several items for individualizing moral foundations were removed due to issues related to the convergent and discriminant validity. More specifically, we failed to observe the discriminant validity for individualizing and binding moral foundations. In exploratory factor analyses, standardized factor loading values for some items in each construct of individualizing and binding moral foundations were too low to constitute valid measures for each dimension of moral foundations. In addition, data produced high correlations among the observed items in authority values and fairness values, which posed a challenge in ensuring discriminant validity. Given that other studies (e.g., Malka et al., 2016) also showed the high correlations between individualizing and binding foundations, we call for future research that improves the measures of moral foundations by ensuring both convergent and discriminant validity. We also call for future research that advance the measures for consumer moral foundations adapted from Haidt's moral foundations that are more oriented to political moral reasoning.

Since we assumed that anger and blame attributions would covary, we did not consider the multiple-step mediation in which anger might be influenced by blame attributions. However, future research may consider such a multiple-step mediation model, considering that "feelings of 
anger are caused by an attributional process consisting of evaluations of an actor's intentions and the amount of control the actor had over the situation" (Quigley \& Tedeschi, 1996, p. 1280).

Lastly, regarding the impact of moral foundations on anti-sweatshop boycotts, the current study did not measure respondents' cognitive appraisals of the potential cost or negative outcomes of such boycotts (Klein et al., 2004). Often, counterarguments in terms of the potential cost of boycotts are used as a defensive strategy by a supplier blamed for appalling working conditions. Future research should examine how cognitive appraisals of such counterarguments interact with moral foundations in predicting boycott intentions.

\section{Conclusions}

Responding to consumer boycotts has become a new business normal for global companies in this social media age. Results of the current research suggest that business managers should take into account the consumer moral foundations when establishing a crisis response strategy for a legally immune yet ethically vulnerable corporate crisis. Previous research $(\mathrm{Xu} \& \mathrm{Li}, 2013)$ recommends a strategy of a full apology, and acceptance of responsibility, for an issue of labor rights violations at an MNC's global supply chain. Mainly, this is because accepting responsibility suppresses the development of emotional anger.

Incorporating blame attributions into the model also has a practical implication for crisis managers. A crisis communication commonly employed in this kind of labor mistreatment case is a denial of any direct legal and ethical violations. For instance, in responding to the spate of suicides, Foxconn adopted the denial strategy and later it deflected the blame onto the suicideattempters themselves (Xu \& Li, 2013).

This study demonstrates that the more US consumers attribute blame to the parent company of an MNC, the likelier they are to engage in boycotts against the MNC for the labor 
right violations that happened at factories in a hosting company. Therefore, communication managers at a headquarter of an MNC should adopt a crisis response strategy based on the accurate assessment of opinions and perceptions of key stakeholders in a home country. They also should be sensitive to word-choice in the official statement, to avoid sounding and seeming irresponsible to the consumers who espouse moral foundations of justice, fairness and care. 


\section{References}

Anner, M. (2012). Corporate social responsibility and freedom of association rights:The precarious quest for legitimacy and control in global supply chains. Politics \& Society, 40(4), 609-644.

Antonetti, P., \& Maklan, S. (2016). An extended model of moral outrage at corporate social irresponsibility. Journal of Business Ethics, 135(3), 429-444.

Banerjee, S. B. (2008). Corporate social responsibility: The good, the bad and the ugly. Critical Sociology, 34(1), 51-79.

Batson, C. D., Kennedy, C. L., Nord, L.-A., Stocks, E. L., Fleming, D. Y. A., Marzette, C. M., . . Zerger, T. (2007). Anger at unfairness: is it moral outrage? European Journal of Social Psychology, 37(6), 1272-1285.

Bliss, T. J. (2002). Citizen advocacy groups: corporate friends or foes. In J. Andriof, S. Waddock, B. Husted \& S. S. Rahman (Eds.), Unfolding stakeholder thinking: Theory, responsibility and engagement (Vol. 1, pp. 251-266). NY: Routledge.

Bradfield, M., \& Aquino, K. (1999). The effects of blame attributions and offender likableness on forgiveness and revenge in the workplace. Journal of Management, 25(5), 607-631.

Braunsberger, K., \& Buckler, B. (2011). What motivates consumers to participate in boycotts: Lessons from the ongoing Canadian seafood boycott. Journal of Business Research, 64(1), 96-102.

Coombs, W. T. (2007). Protecting organization reputations during a crisis: The development and application of situational crisis communication theory. Corporate Reputation Review, $10(3), 163-176$. 
Crone, D. L., \& Laham, S. M. (2015). Multiple moral foundations predict responses to sacrificial dilemmas. Personality and Individual Differences, 85, 60-65.

De Backer, C. J. S., \& Hudders, L. (2015). Meat morals: relationship between meat consumption consumer attitudes towards human and animal welfare and moral behavior. Meat Science, $99(0), 68-74$.

Donoghue, S., \& de Klerk, H. M. (2013). Consumers' anger and coping strategies following appraisals of appliance failure. International Journal of Consumer Studies, 37(2), 214221.

Donoghue, S., Strydom, N., Andrews, L., Pentecost, R., \& de Klerk, H. M. (2016). Differences between Black and White South Africans in product failure attributions, anger and complaint behaviour. International Journal of Consumer Studies, 40(3), 257-267.

Fornell, C., \& Larcker, D. F. (1981). Evaluating structural equation models with unobservable variables and measurement error. Journal of Marketing Research, 18(1), 39-50.

Friedman, M. (1991). Consumer boycotts: A conceptual framework and research agenda. Journal of social Issues, 47(1), 149-168.

Ghoshal, S., \& Bartlett, C. A. (1990). The multinational corporation as an interorganizational network. Academy of Management Review, 15(4), 603-626.

Gibson, D. E., \& Callister, R. R. (2010). Anger in Organizations: Review and Integration. Journal of Management, 36(1), 66-93.

Graham, J., Haidt, J., \& Nosek, B. A. (2009). Liberals and conservatives rely on different sets of moral foundations. Journal of Personality and Social Psychology, 96(5), 1029-1046.

Graham, J., Nosek, B. A., Haidt, J., Iyer, R., Koleva, S., \& Ditto, P. H. (2011). Mapping the moral domain. Journal of Personality and Social Psychology, 101(2), 366-385. 
Grappi, S., Romani, S., \& Bagozzi, R. P. (2013). Consumer response to corporate irresponsible behavior: Moral emotions and virtues. Journal of Business Research, 66(10), 1814-1821.

Grégoire, Y., \& Fisher, R. J. (2008). Customer betrayal and retaliation: when your best customers become your worst enemies. Journal of the Academy of Marketing Science, $36(2), 247-261$.

Haidt, J., \& Graham, J. (2007). When morality opposes justice: Conservatives have moral intuitions that liberals may not recognize. Social Justice Research, 20(1), 98-116.

Hayes, A. F. (2009). Beyond Baron and Kenny: Statistical mediation analysis in the new Millennium. Communication Monographs, 76(4), 408-420.

Hoffmann, S., \& Müller, S. (2009). Consumer boycotts due to factory relocation. Journal of Business Research, 62(2), 239-247.

Hosmer, L. T., \& Kiewitz, C. (2005). Organizational justice: A behavioral science concept with critical implications for business ethics and stakeholder theory. Business Ethics Quarterly, 15(1), 67-91.

Hu, L.-T., \& Bentler, P. M. (1999). Cutoff criteria for fit indexes in covariance structure analysis: Conventional criteria versus new alternatives. Structural Equation Modeling, $6(1), 1-55$.

Hume, D. (2006). An enquiry concerning the principles of morals: a critical edition. London: Oxford University Press.

John, A., \& Klein, J. (2003). The boycott puzzle: Consumer motivations for purchase sacrifice. Management Science, 49(9), 1196-1209. 
Kähr, A., Nyffenegger, B., Krohmer, H., \& Hoyer, W. D. (2016). When hostile consumers wreak havoc on your brand: The phenomenon of consumer brand sabotage. Journal of Marketing, 80(3), 25-41.

Kidwell, B., Farmer, A., \& Hardesty, D. M. (2013). Getting liberals and conservatives to go green: Political ideology and congruent appeals. Journal of Consumer Research, 40(2), 350-367.

Klein, J. G., Smith, N. C., \& John, A. (2004). Why we boycott: consumer motivations for boycott participation. Journal of Marketing, 68(3), 92-109.

Lawrence, A. T. (2002). The drivers of stakeholder engagement: reflections on the case of Royal Dutch/Shell *. In J. Andriof, S. Waddock, B. Husted \& S. S. Rahman (Eds.), Unfolding stakeholder thinking: Theory, responsibility and engagement (pp. 185-199). UK: Greenleaf Publishing.

Lim, J. S. (2010). Global integration or local responsiveness? Multinational corporations’ public relations strategies and tactics. In G. J. Golan, T. J. Johnson \& W. Wanta (Eds.), International media communication in a global age (pp. 299-318). NY: Routledge.

Lim, J. S. (2017). How a paracrisis situation is instigated by an online firestorm and visual mockery: Testing a paracrisis development model. Computers in Human Behavior, 67, 252-263.

Lindenmeier, J., Schleer, C., \& Pricl, D. (2012). Consumer outrage: Emotional reactions to unethical corporate behavior. Journal of Business Research, 65(9), 1364-1373.

Low, M., \& Wui, M. G. L. (2016). Moral foundations and attitudes towards the poor. Current Psychology, 35(4), 650-656. 
Makarem, S. C., \& Jae, H. (2016). Consumer boycott behavior: an exploratory analysis of Twitter feeds. Journal of Consumer Affairs, 50(1), 193-223.

Malka, A., Osborne, D., Soto, C. J., Greaves, L. M., Sibley, C. G., \& Lelkes, Y. (2016). Binding moral foundations and the narrowing of ideological conflict to the traditional morality domain. Personality and Social Psychology Bulletin, 42(9), 1243-1257.

Markowitz, E. M., \& Shariff, A. F. (2012). Climate change and moral judgement. Nature Climate Change, 2, 243.

Molleda, J.-C., Connolly-Ahern, C., \& Quinn, C. (2005). Cross-national conflict shifting: expanding a theory of global public relations management through quantitative content analysis. Journalism Studies, 6(1), 87-102.

Molleda, J.-C., \& Quinn, C. (2004). Cross-national conflict shifting: a global public relations dynamic. Public Relations Review, 30(1), 1-9.

Munshi, D., \& Kurian, P. (2005). Imperializing spin cycles: A postcolonial look at public relations, greenwashing, and the separation of publics. Public Relations Review, 31(4), 513-520.

Muthén, L. K., \& Muthén, B. O. (1998-2012). Mplus user's guide (7th ed.). Los Angeles, CA: Muthén \& Muthén.

Nerb, J., \& Spada, H. (2001). Evaluation of environmental problems: A coherence model of cognition and emotion. Cognition and Emotion, 15(4), 521-551.

Nunnally, J. C., \& Bernstein, I. H. (1994). Psychometric theory (3rd ed.). NY: McGraw-Hill.

O'Mara, E. M., Jackson, L. E., Batson, C. D., \& Gaertner, L. (2011). Will moral outrage stand up?: Distinguishing among emotional reactions to a moral violation. European Journal of Social Psychology, 41(2), 173-179. 
Preacher, K., \& Hayes, A. (2008). Asymptotic and resampling strategies for assessing and comparing indirect effects in multiple mediator models. Behavior Research Methods, 40(3), 879-891.

Quigley, B. M., \& Tedeschi, J. T. (1996). Mediating effects of blame attributions on feelings of anger. Personality and Social Psychology Bulletin, 22(12), 1280-1288.

Ruggie, J. G. (2004). Reconstituting the global public domain — Issues, actors, and practices. European Journal of International Relations, 10(4), 499-531.

Russell, C. A., Russell, D. W., \& Honea, H. (2016). Corporate social responsibility failures: How do consumers respond to corporate violations of implied social contracts. Journal of Business Ethics, 136(4), 759-773.

Scherer, A. G., Palazzo, G., \& Baumann, D. (2006). Global rules and private actors: Toward a new role of the transnational corporation in global governance. Business Ethics Quarterly, 16(4), 505-532.

Schmalz, S., \& Orth, U. R. (2012). Brand attachment and consumer emotional response to unethical firm behavior. Psychology \& Marketing, 29(11), 869-884.

Schwarz, A., \& Fritsch, A. (2014). Communicating on behalf of global civil society: Management and coordination of public relations in international nongovernmental organizations. Journal of Public Relations Research, 26(2), 161-183.

Sen, S., Gurhan-Canli, Z., \& Morwitz, V. (2001). Withholding consumption: A social dilemma perspective on consumer boycotts. Journal of Consumer Research, 28(3), 399-417.

Smith, I. H., Aquino, K., Koleva, S., \& Graham, J. (2014). The moral ties that bind . . even to out-groups. Psychological Science, 25(8), 1554-1562. 
Stephens, N., \& Gwinner, K. P. (1998). Why don't some people complain? A cognitive-emotive process model of consumer complaint behavior. Journal of the Academy of Marketing Science, 26(3), 172-189.

Taylor, M. (2000). Cultural variance as a challenge to global public relations: A case study of the Coca-Cola scare in Europe. Public Relations Review, 26(3), 277-293.

Vassilikopoulou, A., Chatzipanagiotou, K., Siomkos, G., \& Triantafillidou, A. (2011). The role of consumer ethical beliefs in product-harm crises. Journal of Consumer Behaviour, $10(5), 279-289$.

Walster, E. (1966). Assignment of responsibility for an accident. Journal of Personality and Social Psychology, 3(1), 73-79.

Watkins, L., Aitken, R., \& Mather, D. (2016). Conscientious consumers: a relationship between moral foundations, political orientation and sustainable consumption. Journal of Cleaner Production, 134, Part A, 137-146.

Wildermuth, C., De Mello e Souza, C. A., \& Kozitza, T. (2017). Circles of ethics: The impact of proximity on moral reasoning. Journal of Business Ethics, 140(1), 17-42.

Winterich, K. P., Zhang, Y., \& Mittal, V. (2012). How political identity and charity positioning increase donations: Insights from moral foundations theory. International Journal of Research in Marketing, 29(4), 346-354.

Xie, C., Bagozzi, R. P., \& Grønhaug, K. (2015). The role of moral emotions and individual differences in consumer responses to corporate green and non-green actions. Journal of the Academy of Marketing Science, 43(3), 333-356.

Xu, K., \& Li, W. (2013). An ethical stakeholder approach to crisis communication: a case study of Foxconn's 2010 employee suicide crisis. Journal of Business Ethics, 117(2), 371-386. 
Yu, X. (2008). Impacts of corporate code of conduct on labor standards: A case study of Reebok's athletic footwear supplier factory in China. Journal of Business Ethics, 81(3), 513-529.

Zourrig, H., Chebat, J.-C., \& Toffoli, R. (2009). Consumer revenge behavior: A cross-cultural perspective. Journal of Business Research, 62(10), 995-1001. 
Table 1

Test of the Measurement Model employing CFA

\begin{tabular}{|c|c|c|c|c|c|}
\hline Factor \& Items & $\begin{array}{c}\text { CFA } \\
\text { item } \\
\text { loading }\end{array}$ & S.E. & t-value & $\mathrm{CR}^{b}$ & $\mathrm{AVE}^{c}$ \\
\hline \multicolumn{6}{|l|}{ Boycotts $(\mathrm{M}=3.66, \mathrm{SD}=1.14, \alpha=.91)$} \\
\hline $\begin{array}{l}\text { BOYC1: I would recommend others to avoid World Jeans' } \\
\text { products. }\end{array}$ & .737 & .015 & $48.41^{* * *}$ & \multirow{6}{*}{.92} & \multirow{6}{*}{.62} \\
\hline $\begin{array}{l}\text { BOYC2: I would discourage friends and family from buying a } \\
\text { product from World Jeans. }\end{array}$ & .798 & .012 & $64.03^{* * *}$ & & \\
\hline $\begin{array}{l}\text { BOYC3: I would distribute negative articles or reports about } \\
\text { World Jeans to my friends/people I know. }\end{array}$ & .689 & .017 & $40.40^{* * * *}$ & & \\
\hline $\begin{array}{l}\text { BOYC4: I would subscribe to a boycott website against World } \\
\text { Jeans' products across the globe. }\end{array}$ & .807 & .012 & $67.35^{* * *}$ & & \\
\hline $\begin{array}{l}\text { BOYC5: I would sign a petition to stop sales of World Jeans' } \\
\text { products in our country. }\end{array}$ & .867 & .009 & $93.33^{* * * *}$ & & \\
\hline $\begin{array}{l}\text { BOYC6: I would sign a petition for legislation ordering World } \\
\text { Jeans to improve its labor conditions. }\end{array}$ & .798 & .012 & $64.55^{* * *}$ & & \\
\hline \multicolumn{6}{|l|}{$\operatorname{Anger}(\mathrm{M}=3.61, \mathrm{SD}=1.04, \alpha=.86)$} \\
\hline ANG1: angry & .744 & .015 & $48.05^{* * *}$ & \multirow{4}{*}{.85} & \multirow{4}{*}{.59} \\
\hline ANG2: irritated & .613 & .021 & $29.76^{* * *}$ & & \\
\hline ANG3: annoyed & .803 & .013 & $62.27^{* * *}$ & & \\
\hline ANG4: upset & .878 & .010 & $87.04^{* * *}$ & & \\
\hline \multicolumn{6}{|l|}{ Blame attribution $(\mathrm{M}=3.91, \mathrm{SD}=.94, \alpha=.86)$} \\
\hline $\begin{array}{l}\text { BA1: World Jeans could have avoided the crisis if they had } \\
\text { taken right actions. }\end{array}$ & .761 & .017 & $44.24^{* * *}$ & \multirow{3}{*}{.84} & \multirow{3}{*}{64} \\
\hline $\begin{array}{l}\text { BA2: World Jeans has enough resources to have prevented the } \\
\text { crisis from occurring. }\end{array}$ & .809 & .015 & $53.43^{* * *}$ & & \\
\hline $\begin{array}{l}\text { BA3: World Jeans' greed to maximize the profit margin is the } \\
\text { primary cause of the crisis. }\end{array}$ & .825 & .014 & $58.68^{* * *}$ & & \\
\hline \multicolumn{6}{|l|}{ Individualizing Moral Values $(\mathrm{M}=4.12, \mathrm{SD}=.83, \alpha=.89)$} \\
\hline INDI: Whether someone was harmed & .801 & .013 & $60.65^{* * *}$ & \multirow{5}{*}{.89} & \multirow{5}{*}{.62} \\
\hline IND2: Whether someone used violence & .738 & .016 & $43.54^{* * * *}$ & & \\
\hline $\begin{array}{l}\text { IND3: Whether some people were treated differently from } \\
\text { others }\end{array}$ & .781 & .014 & $55.54^{* * *}$ & & \\
\hline IND4: Whether someone was denied his/her rights & .803 & .013 & $62.18^{* * *}$ & & \\
\hline IND5: Whether someone acted unfairly & .816 & .013 & $65.18^{* * *}$ & & \\
\hline \multicolumn{6}{|l|}{${ }^{a}$ Standardized estimates } \\
\hline${ }^{b}$ Composite reliability & & & & & \\
\hline Average Variance Extı & & & & & \\
\hline
\end{tabular}


Table 2

Means, standard deviations, and estimated correlation matrix for the latent variables

\begin{tabular}{|c|c|c|c|c|c|c|}
\hline & M & SD & BOYC & ANG & BA & INDI \\
\hline BOYC & 3.66 & 1.14 & $\mathbf{. 7 8}$ & & & \\
\hline ANG & 3.61 & 1.04 & .74 & .77 & & \\
\hline BA & 3.91 & .94 & .75 & .77 &. $\mathbf{8 0}$ & \\
\hline INDI & 4.12 & .83 & .42 & .42 & .51 & .81 \\
\hline
\end{tabular}

Note: BOYC: boycotts; ANG: anger; BA: blame attributions; INDI: individualizing moral values. Square root of AVE is on the diagonal. 
Table 3

Results of Mediation Analysis with Structural Equation Modeling

\begin{tabular}{|l|c|c|c|}
\hline \multicolumn{4}{|l|}{ Structural equation model } \\
\hline Paths & Estimate & S.E. & Z \\
\hline INDI $\rightarrow$ BA & .512 & .03 & $18.83^{\text {*** }}$ \\
\hline INDI $\rightarrow$ ANG & .422 & .029 & $14.64^{\text {*** }}$ \\
\hline INDI $\rightarrow$ BOYC & .022 & .026 & .842 \\
\hline BA $\rightarrow$ BOYC & .240 & .044 & $5.435^{\text {*** }}$ \\
\hline ANG $\rightarrow$ BOYC & .651 & .038 & $16.914^{* * *}$ \\
\hline
\end{tabular}

\begin{tabular}{|c|c|c|c|c|c|}
\hline \multicolumn{6}{|c|}{ Mediation analysis } \\
\hline & \multicolumn{3}{|c|}{ Indi $\rightarrow$ BOYC through BA \& ANG } & \multicolumn{2}{|c|}{$\mathrm{BC} 95 \% \mathrm{CI}$} \\
\hline & Estimate & S.E. & $\mathrm{Z}$ & Lower & Upper \\
\hline Total Effect & .419 & .035 & $12.115^{* * *}$ & .351 & .487 \\
\hline Total Indirect & .397 & .033 & $12.136^{* * *}$ & .333 & .462 \\
\hline Direct & .022 & .027 & .790 & -.032 & .067 \\
\hline $\begin{array}{l}\text { Specific: INDI } \\
\rightarrow \text { ANG } \rightarrow \text { BOYC }\end{array}$ & .274 & .032 & $8.665^{* * *}$ & .212 & .336 \\
\hline $\begin{array}{l}\text { Specific: INDI } \\
\rightarrow \mathrm{BA} \rightarrow \mathrm{BOYC}\end{array}$ & .123 & .028 & $4.467^{* * *}$ & .069 & .177 \\
\hline
\end{tabular}

Note $: \chi^{2}=400.31, \mathrm{df}=126, \chi^{2} / \mathrm{df}=3.18, \mathrm{SRMR}=.03, \mathrm{RMSEA}=.044$ [90\% CI=.039-.049], CFI $=.98, \mathrm{TLI}=.97, \mathrm{SRMR}=.03 . \mathrm{BC} 95 \% \mathrm{CI}$ : Bias-corrected $95 \%$ bootstrapped confidence interval (CI) based on 5,000 resamples.

$* p<.05, * * p<.01, * * * p<.001$. 


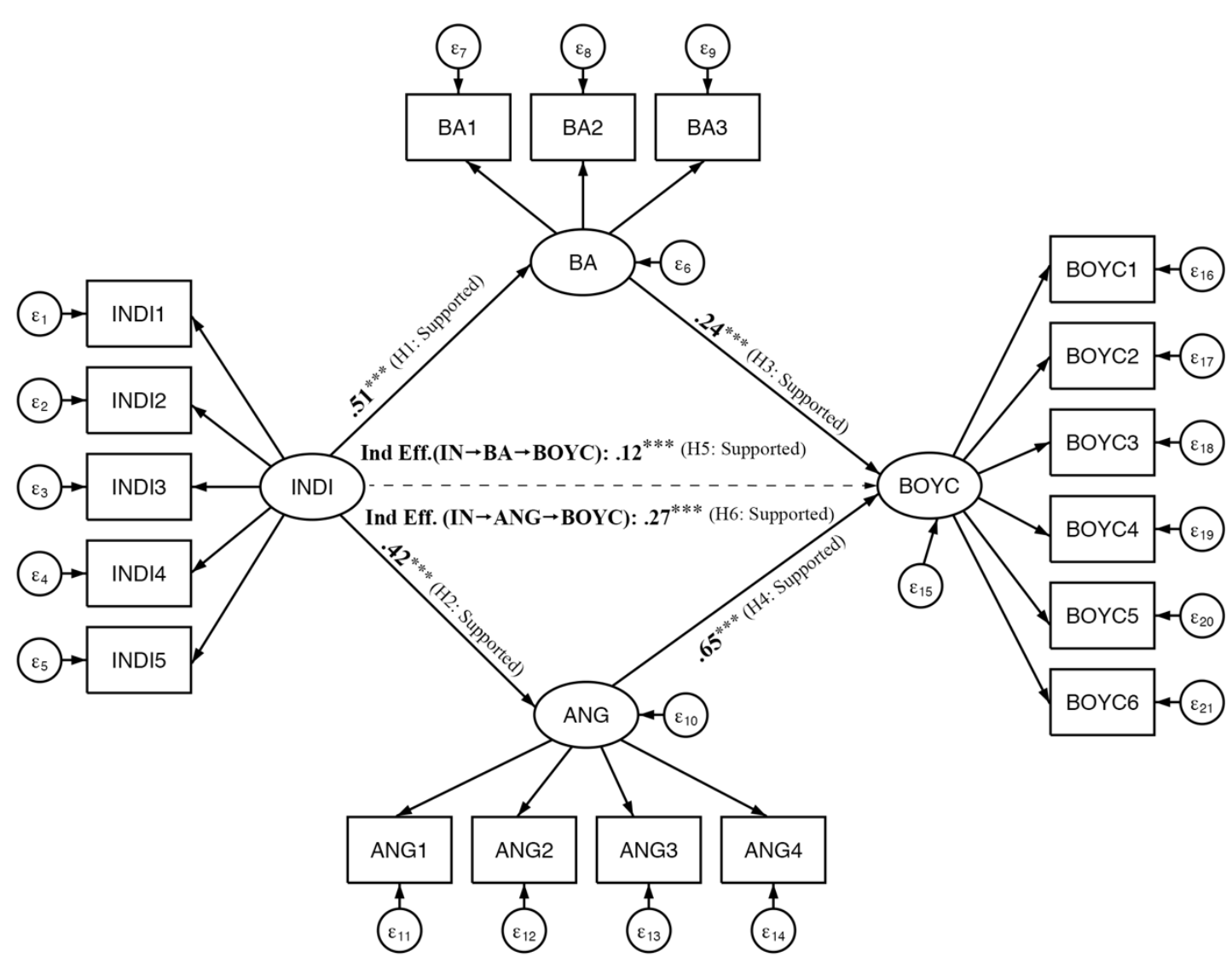

Figure 1. Path diagrams of SEM to test the effect of individualizing moral values on boycott intentions mediated by blame attribution and anger. BOYC: boycotts; ANG: anger; BA: blame attributions; INDI: individualizing moral values. Ind Eff. Indicates a specific indirect effect. The mediation analysis is based on Bias-corrected $95 \%$ bootstrapped confidence interval (CI) based on 5,000 resamples. $* * * p<.001$. 